American J. of Engineering and Applied Sciences 4 (1): 66-69, 2011

ISSN 1941-7020

(C) 2010 Science Publications

\title{
Effect of Ethanol Addition in the Combustion Process During Warm-UPS and Half Open Throttle on Port-Injection Gasoline Engine
}

\author{
${ }^{1}$ Beny Cahyono and ${ }^{2}$ Rosli Abu Bakar \\ ${ }^{1}$ Department of Marine Engineering, Faculty of Ocean Engineering, ITS, Surabaya, Indonesia \\ ${ }^{2}$ Department of Mechanical Engineering, Faculty of Mechanical Engineering, \\ University Malaysia Pahang, Pahang, Malaysia
}

\begin{abstract}
Problem statement: Ethanol is an alternative fuel with huge potential that can be used in gasoline engines. Addition of ethanol in fuel will affect the fuel properties, fuel properties change will affect the engine performance. Approach: To determine the effect of adding ethanol to gasoline engines, in this study are tested using gasoline, ethanol 10 and $20 \%$ ethanol. Results: Testing is done at the time of warm-ups and half-open throttle. From the experiment will know adding ethanol in the process of warming-up and half-open throttle was a decline emission, at half open throttle will increase $\mathrm{CO}_{2}$ emissions and reduce $\mathrm{HC}$ and $\mathrm{CO}$, during warm-ups that while the increased $\mathrm{CO}$ but decreases $\mathrm{CO}_{2}$. Conclusion/Recommendations: Although experiments on the throttle partially open, the test under $3000 \mathrm{rpm}$ using 10 and $20 \%$ ethanol will reduce power, but at $3500 \mathrm{rpm}$ to increase engine power.
\end{abstract}

Key words: Ethanol, port injection, performance, emission, warm-up, half open throttle

\section{INTRODUCTION}

The energy crisis, there are a lot of alternative fuel appears as future fuel. With this alternative fuel is Expected replace the existing fuel today. Apart from the type of fuel that can be replaced, the fuel is expected to be more environmentally friendly. One of the many Alternative Fuels, ethanol is can replace gasoline (Hu et al., 2007; Liu et al., 2007; Yuksel and Yuksel, 2004).

Alcohol fuels and particularly ethanol can be produced from renewable sources, such as sugar cane, cassava, many types of waste biomass materials, corn and barley. Ethanol has some advantages over gasoline, such as the reduction of $\mathrm{CO}$, Volatile Organic Compounds (VOC) and Unburned Hydrocarbon (UHC) emissions and better anti-knock characteristics, which allow for the use of higher compression ratio of engines. Since ethanol is a liquid fuel, the storage and dispensing of ethanol is similar to that of gasoline.

At the present time ethanol is used in spark ignition engines by blending with gasoline at low concentrations without any modification. Pure ethanol can be used in spark ignition engines but necessitates some modifications to the engine.

Yucesu et al. (2006). Investigated the effects of ethanol-gasoline blends (E0, E10, E20, E30, E40, E60) on gasoline engine performance and exhaust emission in different compression ratio. According to the results of the experiment, it was found that as the compression ratio increased, engine torque and $\mathrm{HC}$ emission also increased. The fuels containing high ratios of ethanol, E40 and E60 had important effect on the reduction of $\mathrm{CO}$ and $\mathrm{HC}$ emission.

Song et al. (2006). Investigated the effect of the additives of ethanol (up to $9.79 \%$ ethanol) and methyl tert butyl ether (up to 20\% MTBE) in various blend ratios into the gasoline fuel on the exhaust emissions in an EFI gasoline engine. The experimental result showed that ethanol broutht about generally lower regulated engine-out emissions (CO, THC and NOx) than MTBE did.

Investigated the behavior of a small four-stroke engine when mixtures of gasoline-ethanol and gasoline-methanol were used as fuel. In the engine tests, 11 test blends ranging from $0 \%$ to $100 \%$ ethanol with an increment of $10 \%$ were used. CO emissions were decreased as ethanol content in fuel increased. Moreover, $\mathrm{HC}$ emissions were decreased as ethanol content in fuel increased, but $\mathrm{HC}$ emissions significantly increased when using E90 and E100 fuel.

In the experimental study of Al-Hasan (2003), the effects of usage of unleaded gasoline-ethanol blends on spark ignition engine performance and exhaust emission were investigated. The result showed that

Corresponding Author: Beny Cahyono, Department of Marine Engineering, Faculty of Ocean Engineering,

ITS, Surabaya, Indonesia 
ethanol addition leads to an increase in brake power, the brake thermal efficiency, volumetric efficiency and fuel consumption by about $8.3 \%, 9 \%, 7 \%$ and $5.7 \%$ mean average values, respectively.

Wu et al. (2004) investigated the effect of air-fuel ratio on SI engine performance and pollutant emission using ethanol-gasoline blends. The result of engine performance test showed that torque output improves when using ethanol-gasoline blends. However, there is no appreciable difference on the brake specific heat consumption. $\mathrm{CO}$ and $\mathrm{HC}$ emissions reduced with the increase of ethanol content in the blended fuel. The maximum $\mathrm{CO}_{2}$ emission was obtained at $\pi \sim 1.01$, but the smallest amount $\mathrm{CO}_{2}$ emission obtained with E30. In their study found out that by using $10 \%$ ethanol fuel, can reduce pollutant emission efficiently.

In this study will be undertaken to determine the effect of ethanol on port-injection gasoline engines in the warm-ups conditions and half-open throttle. The data collection is done during warm-ups and also halfopen throttle. Purpose of this experiment is to know the level of emissions caused by the addition of ethanol in the fuel when warm-up and cruising conditions

\section{MATERIALS AND METHODS}

Experiment apparatus included three major systems, i.e. the engine system, the power system and the exhaust measurement system. Engine used in this experiment is Mitsubishi 4G92 engine four-cylinder port injection. With the specification as follows:

$\begin{array}{ll}\text { Merck } & : \text { Mitsubishi } \\ \text { Type } & : \text { In-line OHV, SOCH } \\ \text { Motor Construction } & : 4 \text { cylinder, water cooled } \\ \text { Stroke } & : 4 \text { strokes } \\ \text { Cylinder bore } & : 81 \mathrm{~mm} \\ \text { Piston stroke } & : 77.5 \mathrm{~mm} \\ \text { Compression ratio } & : 10: 1 \\ \text { Volume displacement } & : 353000 \mathrm{~mm}^{3}\end{array}$

To measure torque and rpm, the engine connected to eddy current dynamometer $100 \mathrm{~kW}$. Engine throttle at connecting with the actuator motor to facilitate process control. Torque and engine speed can be seen on the throttle control Fig. 1. Shows the engine stand and instruments used in the experiment

To determine the effect of adding ethanol to gasoline engines, in this experiment will be doing testing on the half-open throttle with the rotation in 2000 up to $5000 \mathrm{rpm}$ with 500 increases. Testing done using fuel with gasoline, ethanol/gasoline blends of 10 and ethanol/gasoline blends $20 \%$. In this experiment will be in getting the data engines torque, power and fuel consumption, exhaust gas emissions both $\mathrm{HC}, \mathrm{CO}$ and $\mathrm{CO}_{2}$.

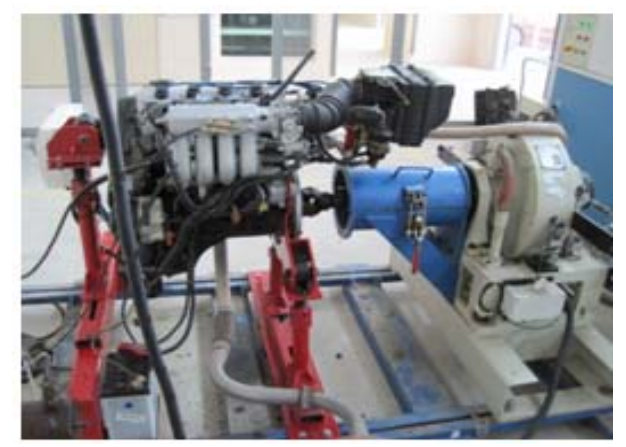

Fig. 1: Engine dynamometer

An emission in the exhaust gas is measured by a portable gas analyzer Kane OIML CLAS 1 (N0356). The working principle of the tool is based absorbstivitas wave infrared radiation from the gas detection. Can detect gas analyzer for $\mathrm{CO}_{2}, \mathrm{CO}, \mathrm{HC}$ and Air fuel ratio. Emissions data collection to be done at start and also at half open throttle, but for the engine power is only half done at open throttle.

\section{RESULTS AND DISCUSSION}

Ethanol as a fuel in the gasoline engine will affect the performance, either during warm-ups or at half open throttle. This study discussed the effect of adding ethanol during warm-ups and also at half open throttle. Experiment is done by connecting the engine with the eddy currents dynamometer.

From tests conducted on $20 \%$ ethanol fuel during warm-ups will result in higher fuel consumption compared with gasoline fuel. For $\mathrm{HC}$ emissions, the $\mathrm{CO}_{2}$ will decrease while the $\mathrm{CO}$ will increase. It can be seen in Fig. 2. In this picture shows the initial start-HC produced by the fuel ethanol/gasoline blend is higher in comparison with gasoline fuel.

At starting condition, engines need a lot of fuel for combustion process. In the Fig. 2 shown, the addition of ethanol 10 or $20 \%$ in the fuel will increase fuel consumption at the start. Increased fuel consumption at start will effect emissions produced. Fuel consumption increase on start caused a lot of fuel that can not be burned to perfection, so that the combustion process will generate a lot of unburned hydrocarbons, this can be seen in the picture above. Where using the higher fuel, produced kana $\mathrm{HC}$ increase and would decrease with increasing time warm-up process.

The use of ethanol as fuel substitution will lead to increased emissions of $\mathrm{CO}$ and $\mathrm{CO}_{2}$ decreases. This occurs because the process of formation of $\mathrm{CO}_{2}$ from the $\mathrm{CO}$ oxidation does not occur. Under load testing condition shows a very different result to the process of warm-ups. Power generated using ethanol 10 and $20 \%$ decrease for low rpm 
operation, with increasing engine rpm power view of the addition of ethanol will raise. This can be seen in Fig. 3, at $2000 \mathrm{rpm}$ until $3000 \mathrm{rpm}$ ethanol 10 and $20 \%$ have less power compared with gasoline, but when the engine speed above $3500 \mathrm{rpm} 20 \%$ ethanol/gasoline blend fuel has more height power. Fuel consumption will increase with increasing amount of ethanol in fuel; it can be seen in Fig. 3, where 20\% ethanol/gasoline blend has a higher fuel consumption compared with $10 \%$ ethanol with fuel or gasoline.

In the Fig. 4 shows the effect of ethanol addition to the exhaust gas emission. At half-open throttle test shows the $\mathrm{CO}$ and $\mathrm{HC}$ will decrease with increasing

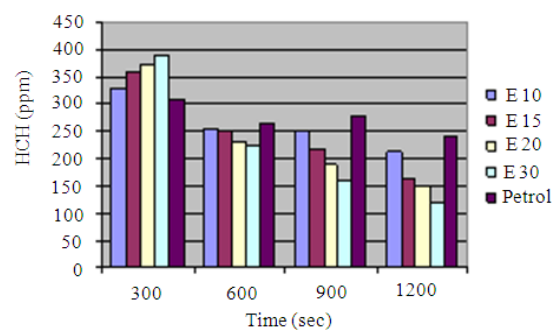

(a)

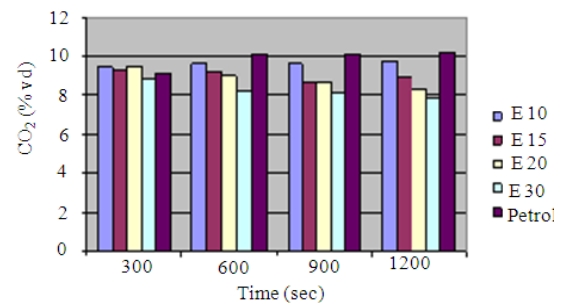

(b)

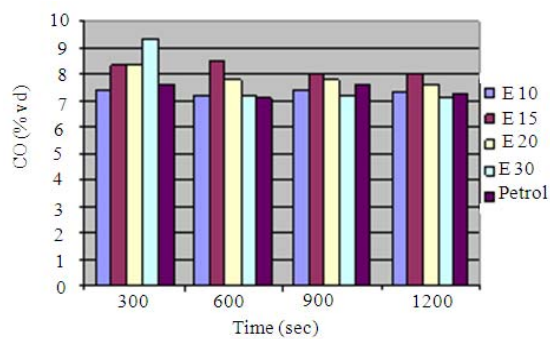

(c)

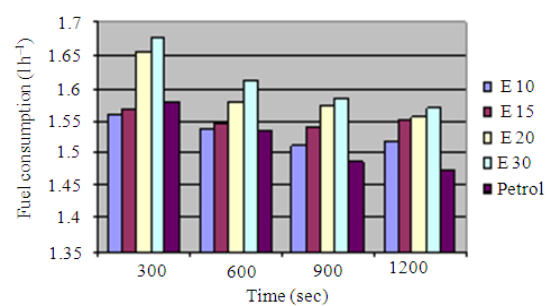

(d)

Fig. 2: Emission and fuel consumption at warm-up amount of ethanol in fuel. 20\% ethanol has a lower $\mathrm{HC}$ compared with $10 \%$ ethanol fuel. To $\mathrm{CO}_{2}$ in this test increases with increasing amount of ethanol in fuel. This is very different from the results in warm-ups, where the process of warm-ups in getting the $\mathrm{HC}$ and $\mathrm{CO}_{2}$ will decrease, but the resulting $\mathrm{CO}$ increase.

At half-open throttle the addition of ethanol in the fuel causes the air fuel ratio can be increased or fuels composition become lean. Increased air fuel ratio affects combustion emissions. This is apparent at half open throttle test that have different emission conditions of warm-ups. In the warm-up conditions, air fuel ratio range in 12, while for the half open throttle range 15 . With high air fuel ratio indicates the amount of oxygen in the bladder in the fuel mixture with air is very high. Oxygen in the combustion process is crucial, so that with sufficient oxygen, the process of combustion in combustion chamber would be more perfect. The combustion process, fuel will be burned to form $\mathrm{CO}_{2}$ and $\mathrm{H}_{2} \mathrm{O}$. Oxygen content in ethanol caused

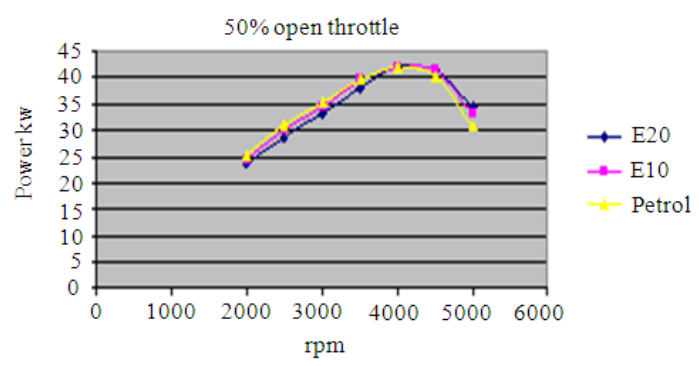

(a)

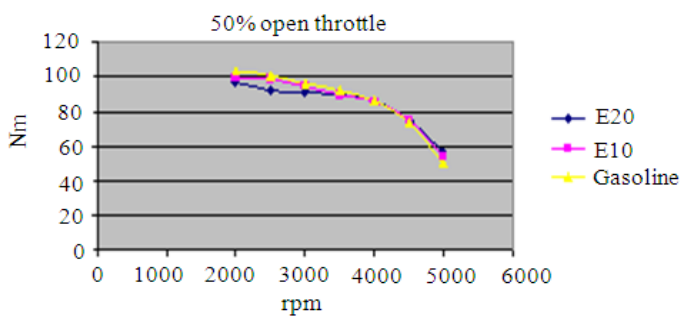

(b)

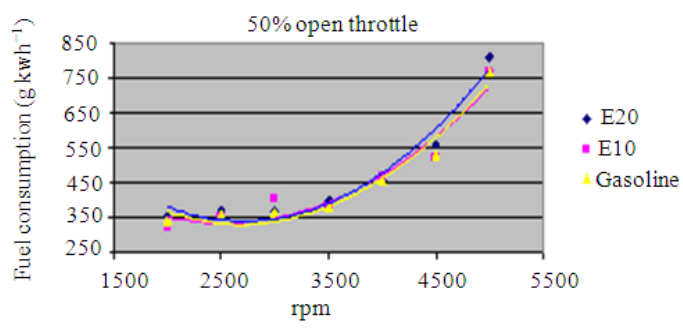

(c)

Fig. 3: Engine performance at half open throttle 


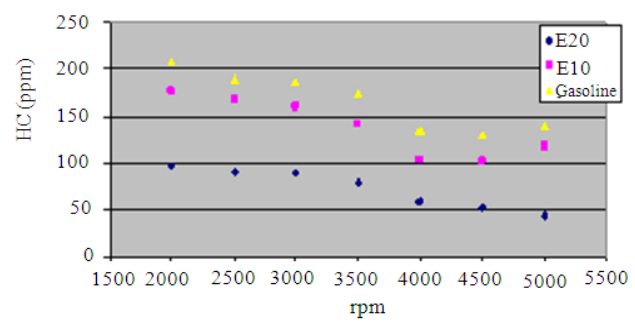

(a)

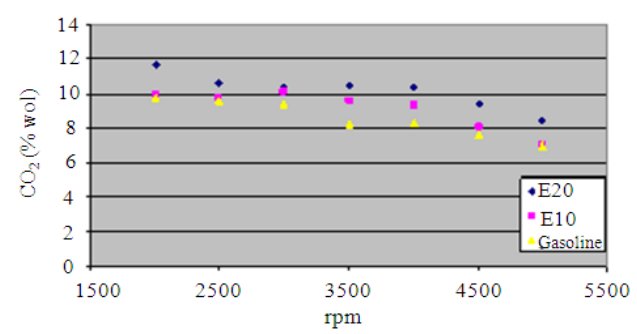

(b)

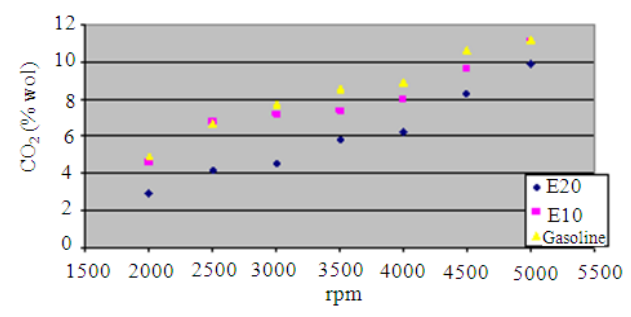

(c)

Fig. 4: Engine emission at half open throttle using different fuel

the amount of oxygen in the combustion process becomes higher. With the increasing oxygen besides improving the combustion process, allowing excess amounts of oxygen for oxidation of $\mathrm{CO}-\mathrm{CO}_{2}$. This is different than the process of warm-ups that have increased $\mathrm{CO}$, where the oxidation process does not happen perfectly. Because the oxygen in the combustion process only enough to burn.

\section{CONCLUSION}

Addition of ethanol 10 and $20 \%$, greatly affect the performance gasoline engines. On experiments conducted on warm-ups and half-open throttle, showed a decrease of power and exhaust gas emissions. Testing by using the half-open throttle, we can determine the addition of ethanol is less suitable for low rpm. Addition of ethanol will be more suitable for high rpm. Emissions generated by ethanol 10 and 20\% showed a decline, both in warm-ups or testing with test load. The higher the concentration of ethanol in fuel will further reduce the emissions produced.

\section{REFERENCES}

Al-Hasan, M., 2003. Effect of ethanol-unleaded gasoline blends on engine performance and exhaust emission. Energy Conversion Manage., 44: 1547-1561. DOI: $10.1016 / \mathrm{S} 0196-8904(02) 00166-8$

Hu, T., Y. Wei, S. Liu and L. Zhou, 2007. Improvement of Spark-Ignition (SI) engine combustion and emission during cold start, fueled with methanol/petrolium blends. J. Energy Fuels. 21: 171-175. DOI: 10.1021/ef0603479

Liu, S., E.R.C. Clemente, T. Hu and Y. Wei, 2007. Study of spark ignition engine fueled with methanol/gasoline fuel blends. J. Applied Thermal Eng., $\quad 27$ : 1904-1910. DOI: 10.1016/j.applthermaleng.2006.12.024

Song, C.L., W.M. Zhang, Y.Q. Pei, G.L. Fan and G.P. Xu, 2006. Comparative effects of MTBE and ethanol additions into gasoline on exhaust emissions. Atmosp. Environ., 40: 1957-1970. DOI: 10.1016/j.atmosenv.2005.11.028

Wu, C.W., R.H. Chen, J.Y. Pu and T.H. Lin, 2004. The influence of air-fuel ratio on engine performance and pollutant emission of an SI engine using ethanol-gasoline blended fuels. Atmospheric Environ., 38: 7093-7100. DOI: 10.1016/j.atmosenv.2004.01.058

Yucesu, H.S., T. Topgul, C. Cinar and M. Okur, 2006. Effect of ethanol-gasoline blends on engine performance and exhaust emissions in different compression ratios. Applied Thermal Engineer., 26: 2272-2278. DOI: 10.1016/j.applthermaleng.2006.03.006

Yuksel, F. and B. Yuksel, 2004. The use of ethanolgasoline blend as a fuel in an SI engine. Renew Energy, 29: 1181-1191. DOI: 10.1016/j.renene.2003.11.012 